Condensed Matter Physics, 1999, Vol. 2, No. 1(17), p. 53-62

\title{
Calculation of distribution functions and diffusion coefficients for ions in the system "initial electrolyte solution - membrane"
}

\author{
R.I.Zhelem, M.V.Tokarchuk, I.P.Omelyan, E.M.Sovyak \\ Institute for Condensed Matter Physics \\ of the National Academy of Sciences of Ukraine, \\ 1 Svientsitskii Str., 290011 Lviv, Ukraine
}

Received July 14, 1998

\begin{abstract}
Diffusion of ions under inhomogeneous conditions in the two-phase system "initial electrolyte solution-membrane" is investigated. Expressions for the friction constant, self- and interdiffusion coefficients are derived by means of a nonequilibrium statistical operator for an inhomogeneous case. They are applied to the system, thus the behaviour of the position-dependent selfdiffusion coefficient for $\mathrm{NaCl}$ near a reverse osmosis membrane is evaluated.
\end{abstract}

Key words: diffusion in liquids, transport processes, distribution function, osmosis, membrane

PACS: $05.60 .+w, 73.40,66.10 . \mathrm{Cb}, 82.65 . \mathrm{Fr}$

\section{Introduction}

Reverse osmosis occupies a significant place among membrane processes for a mixture or electrolyte solution separation into components [1-11]. In contrast to other separation methods, reverse osmosis across a membrane occurs at a molecular level. In this process a membrane plays the role of a specific selective barrier and puts through itself primarily certain components from the solution to be separated. The selectivity of reverse osmosis considerably depends on an interaction of ions and solution molecules with the molecules and components (as membranes are composite materials) of the membrane on its surface and inside. In this connection, in order to describe, forecast and improve the separation in modern devices it is important to work out a nonequilibrium statistical theory for reverse osmosis coupled with computer simulation on the basis of an equivalent account of both solution particles and membrane structure. Spatial inhomogeneity of the system should be considered too. In [12], an analytical calculation of generalized diffusion 
coefficients was performed for ions and molecules in the three-phase system "initial electrolyte solution-membrane" filtrate. It turned out that all diffusion coefficients could be expressed through equilibrium singlet and pair distribution functions. Their evaluation is a complex problem of statistical mechanics. So [13] was aimed at obtaining qualitative distribution functions for the beginning of the separation process when the dissolved ions are located on one side of the reverse osmosis membrane only. Then, it suffices to consider the two-phase system "initial electrolyte solution-membrane". In addition, the description is simplified by assuming the solvent and the membrane to be continuous diffusive media with appropriate dielectric constants $\varepsilon_{1}>\varepsilon_{2}$, whereas ions are represented by charged hard spheres.

Here we are based on the same model. First, we complete the mathematics on inhomogeneous self- and interdiffusion coefficients and arrive at the expression for a friction constant. In the next chapter we apply the result to the model of the reverse osmosis membrane and, using the known distribution functions, evaluate positiondependent self-diffusion coefficients for the two-phase system "initial electrolyte solution-membrane".

\section{Inhomogeneous diffusion coefficients for ions in a two-pha- se system "initial electrolyte solution-membrane"}

In papers [11,12], generalized diffusion equations were obtained for the solution transport through reverse osmosis membranes by means of the Zubarev nonequilibrium statistical operator. We will consider Markovian processes for ionic diffusion when the flux of $k$-species particles in phase $l$ is described by the equation:

$$
\hat{j}^{k}\left(\boldsymbol{r}_{l} ; t\right)=-\sum_{k^{\prime}} \sum_{l^{\prime}} \int_{V_{l^{\prime}}} \mathrm{d} \boldsymbol{r}_{l}^{\prime} D^{k k^{\prime}}\left(\boldsymbol{r}_{l}, \boldsymbol{r}_{l^{\prime}}\right) \frac{\partial}{\partial \boldsymbol{r}_{l^{\prime}}} \delta n^{k^{\prime}}\left(\boldsymbol{r}_{l^{\prime}} ; t\right),
$$

where

$$
\begin{aligned}
& D^{k k^{\prime}}\left(\boldsymbol{r}_{l}, \boldsymbol{r}_{l^{\prime}}\right)= \\
& =\sum_{k^{\prime \prime}} \sum_{l^{\prime \prime}} \int_{V_{l^{\prime \prime}}} \mathrm{d} \boldsymbol{r}_{l^{\prime \prime}} \int_{0}^{\infty} \mathrm{d} t\left\langle\left(1-\mathcal{P}_{0}\right) \hat{\boldsymbol{j}}^{k}\left(\boldsymbol{r}_{l}\right) T_{0}(t)\left(1-\mathcal{P}_{0}\right) \hat{\boldsymbol{j}}^{k^{\prime \prime}}\left(\boldsymbol{r}_{l^{\prime \prime}}\right)\right\rangle_{0} \\
& \times\left[\tilde{\Phi}_{n n}^{-1}\left(\boldsymbol{r}_{l^{\prime \prime}}, \boldsymbol{r}_{l^{\prime}}\right)\right]_{k^{\prime \prime} k^{\prime}}
\end{aligned}
$$

are normalized inhomogeneous diffusion coefficients for the particles of species $k$, $k^{\prime}$ in phases $l, l^{\prime} . \delta n^{k^{\prime}}\left(\boldsymbol{r}_{l^{\prime}} ; t\right)=\left\langle\hat{n}^{k^{\prime}}\left(\boldsymbol{r}_{l^{\prime}}\right)\right\rangle^{t}-\left\langle\hat{n}^{k^{\prime}}\left(\boldsymbol{r}_{l^{\prime}}\right)\right\rangle_{0}$ is a deviation of the density profile from its equilibrium value $\left\langle\hat{n}^{k^{\prime}}\left(\boldsymbol{r}_{l^{\prime}}\right)\right\rangle_{0}=\frac{N_{l^{\prime}}^{k^{\prime}}}{V_{l^{\prime}}} f_{1}^{k^{\prime}}\left(\boldsymbol{r}_{l^{\prime}}\right)$, which is a moving force of diffusion. The indices $l, l^{\prime}$ stand for the phases: 1-initial electrolyte solution, $2-$ membrane, 3 -filtrate. It is naturally to assume that $\sum_{l^{\prime \prime}}$ concerns the neighbouring phases only, as the correlation between the initial solution and filtrate is negligible. In equation (2), $\mathcal{P}_{0}$ is a Mori projection operator and $T_{0}(t)$ is an evolution operator defined in [13], which takes into account the projection. 
To make use of these formulas we focus our attention on the inverse functions $\left[\tilde{\Phi}_{n n}^{-1}\left(\boldsymbol{r}_{l}, \boldsymbol{r}_{l^{\prime}}\right)\right]_{k k^{\prime}}$ to be determined by the relations:

$$
\sum_{k^{\prime}} \sum_{l^{\prime}} \int \mathrm{d} \boldsymbol{r}_{l^{\prime}} \Phi_{n n}^{k k^{\prime}}\left(\boldsymbol{r}_{l}, \boldsymbol{r}_{l^{\prime}}\right)\left[\tilde{\Phi}_{n n}^{-1}\left(\boldsymbol{r}_{l^{\prime}}, \boldsymbol{r}_{l^{\prime \prime}}\right)\right]_{k^{\prime} k^{\prime \prime}}=\delta_{k k^{\prime \prime}} \delta\left(\boldsymbol{r}_{l}-\boldsymbol{r}_{l^{\prime \prime}}\right)
$$

where

$$
\Phi_{n n}^{k k^{\prime}}\left(\boldsymbol{r}_{l}, \boldsymbol{r}_{l^{\prime}}\right)=\left\langle\delta \hat{n}^{k}\left(\boldsymbol{r}_{l}\right) \delta \hat{n}^{k^{\prime}}\left(\boldsymbol{r}_{l^{\prime}}\right)\right\rangle_{0}
$$

are connected with the total correlation function $h_{2}^{k k^{\prime}}\left(\boldsymbol{r}_{l}, \boldsymbol{r}_{l^{\prime}}\right)$. To find an explicit form for $\left[\tilde{\Phi}_{n n}^{-1}\left(\boldsymbol{r}_{l}, \boldsymbol{r}_{l^{\prime}}\right)\right]_{k k^{\prime}}$ it is necessary to consider the details of the model for the membrane, solution and initial diffusion conditions.

The initial solution is supposed to be a two-species system of charged hard spheres of equal valency $Z_{+}=\left|Z_{-}\right|=Z$ and size $\sigma$ in a continuous medium with dielectric constant $\varepsilon_{1}$. The membrane is modelled by a hard wall with dielectric constant $\varepsilon_{2}$. Here $\varepsilon_{1}>\varepsilon_{2}$. Then ions located in the vicinity of the membrane suffer intensive repulsion caused by electrostatic images, i.e. negative adsorption, which is confirmed by equilibrium density profiles of the system (see the next chapter). The phenomenon produces a potential barrier which does not allow the salt ions to penetrate the membrane phase. Consequently, initial conditions for equilibrium concentrations of ions in various phases are to be the following:

$$
\left\langle\hat{n}^{k}\left(\boldsymbol{r}_{1}\right)\right\rangle_{0} \neq 0, \quad\left\langle\hat{n}^{k}\left(\boldsymbol{r}_{2}\right)\right\rangle_{0}=0, \quad\left\langle\hat{n}^{k}\left(\boldsymbol{r}_{3}\right)\right\rangle_{0}=0
$$

They show an absence of ions in the membrane and filtrate phases at the beginning of a diffusion process. It means that

$$
\Phi_{n n}^{k k^{\prime}}\left(\boldsymbol{r}_{l}, \boldsymbol{r}_{l^{\prime}}\right)=\left\{\begin{array}{l}
\equiv 0, \quad l \neq l^{\prime} \\
\neq 0, \quad l=l^{\prime}=1
\end{array} .\right.
$$

So, having in mind that all nonzero quantities concern the initial electrolyte solution only, we omit the both phase indices $l, l^{\prime}$ and the sum over them in (1)-(3). It should be noted that in doing so the important membrane influence (negative adsorption) is not excluded, namely, it affects $h_{2}^{k k^{\prime}}\left(\boldsymbol{r}_{l}, \boldsymbol{r}_{l^{\prime}}\right)$ and, according to (3), $\Phi_{n n}^{k k^{\prime}}\left(\boldsymbol{r}, \boldsymbol{r}^{\prime}\right)$ as well. To determine the latter we make use of the relationship:

$$
\Phi_{n n}^{k k^{\prime}}\left(\boldsymbol{r}, \boldsymbol{r}^{\prime}\right)=\frac{\delta\left\langle\hat{n}^{k}(\boldsymbol{r})\right\rangle_{0}}{\delta \ln z^{k^{\prime}}\left(\boldsymbol{r}^{\prime}\right)}
$$

where $z^{k^{\prime}}\left(\boldsymbol{r}^{\prime}\right)$ is an inhomogeneous activity of a $k^{\prime}$-species particle. Then, equation (3) $l=l^{\prime}=l^{\prime \prime}=1$ can be represented as

$$
\sum_{k^{\prime \prime}} \int \mathrm{d} \boldsymbol{r}^{\prime \prime} \frac{\delta\left\langle\hat{n}^{k}(\boldsymbol{r})\right\rangle_{0}}{\delta \ln z^{k^{\prime \prime}}\left(\boldsymbol{r}^{\prime \prime}\right)} \frac{\delta \ln z^{k^{\prime \prime}}\left(\boldsymbol{r}^{\prime \prime}\right)}{\delta\left\langle\hat{n}^{k^{\prime}}\left(\boldsymbol{r}^{\prime}\right)\right\rangle_{0}}=\delta_{k k^{\prime}} \delta\left(\boldsymbol{r}-\boldsymbol{r}^{\prime}\right)
$$


this is a trivial Ornstein-Zernike equation, while the unknown function $\left[\Phi_{n n}^{-1}\left(\boldsymbol{r}_{l}, \boldsymbol{r}_{l^{\prime}}\right)\right]_{k k^{\prime}}$ is expressed in terms of direct correlations $c_{2}^{k k^{\prime}}\left(\boldsymbol{r}, \boldsymbol{r}^{\prime}\right)[14,15]$ :

$$
\frac{\delta \ln z^{k}(\boldsymbol{r})}{\delta\left\langle\hat{n}^{k^{\prime}}\left(\boldsymbol{r}^{\prime}\right)\right\rangle_{0}}=\left[\Phi_{n n}^{-1}\left(\boldsymbol{r}_{l}, \boldsymbol{r}_{l^{\prime}}\right)\right]_{k k^{\prime}}=\frac{\delta_{k k^{\prime}} \delta\left(\boldsymbol{r}-\boldsymbol{r}^{\prime}\right)}{\left\langle\hat{n}^{k^{\prime}}\left(\boldsymbol{r}^{\prime}\right)\right\rangle_{0}}-c_{2}^{k k^{\prime}}\left(\boldsymbol{r}, \boldsymbol{r}^{\prime}\right) .
$$

The solution obtained is exact, however, $c_{2}^{k k^{\prime}}\left(\boldsymbol{r}, \boldsymbol{r}^{\prime}\right)$ serves as a basic function in the equilibrium theory for calculating structural distribution functions. It is usually approximated (PY, HNC approximations, their modifications [14,15]) to have the total correlation function $h_{2}^{k k^{\prime}}\left(\boldsymbol{r}, \boldsymbol{r}^{\prime}\right)$ with the help of the Ornstein-Zernike equation.

We are going to perform a calculation of inhomogeneous diffusion coefficients for ions (2) in the Gaussian approximation for the time correlation function $\langle(1-$ $\left.\left.\mathcal{P}_{0}\right) \hat{\boldsymbol{j}}^{k}\left(\boldsymbol{r}_{l}\right) T_{0}(t)\left(1-\mathcal{P}_{0}\right) \hat{\boldsymbol{j}}^{k^{\prime \prime}}\left(\boldsymbol{r}_{l^{\prime \prime}}\right)\right\rangle_{0}$, then, in accordance with [12] one arrives at

$$
D^{k k^{\prime}}\left(\boldsymbol{r}, \boldsymbol{r}^{\prime}\right)=\int_{0}^{\infty} \mathrm{d} \tau \lambda_{0}^{k k^{\prime}}\left(\boldsymbol{r}, \boldsymbol{r}^{\prime}\right) \exp \left\{-\frac{\lambda_{2}^{k k^{\prime}}\left(\boldsymbol{r}, \boldsymbol{r}^{\prime}\right)}{2 !} \tau^{2}\right\}=\lambda_{0}^{k k^{\prime}}\left(\boldsymbol{r}, \boldsymbol{r}^{\prime}\right) \sqrt{\frac{\pi}{2 \bar{\lambda}_{2}^{k k^{\prime}}\left(\boldsymbol{r}, \boldsymbol{r}^{\prime}\right)}}
$$

where $\lambda_{0}^{k k^{\prime}}\left(\boldsymbol{r}, \boldsymbol{r}^{\prime}\right)$ and $\lambda_{2}^{k k^{\prime}}\left(\boldsymbol{r}, \boldsymbol{r}^{\prime}\right)$ are obtained in [13] and have the form:

$$
\begin{aligned}
\lambda_{0}^{k k^{\prime}}\left(\boldsymbol{r}, \boldsymbol{r}^{\prime}\right)= & \sum_{k^{\prime \prime}} \int \mathrm{d} \boldsymbol{r}^{\prime \prime}\left\langle\left(1-\mathcal{P}_{0}\right) \hat{\boldsymbol{j}}^{k}\left(\boldsymbol{r}_{l}\right) T_{0}(t)\left(1-\mathcal{P}_{0}\right) \hat{\boldsymbol{j}}^{k^{\prime \prime}}\left(\boldsymbol{r}_{l^{\prime \prime}}\right)\right\rangle_{0} \\
& \times\left(\frac{\delta_{k^{\prime \prime} k^{\prime}} \delta\left(\boldsymbol{r}^{\prime \prime}-\boldsymbol{r}^{\prime}\right)}{\left\langle\hat{n}^{k^{\prime \prime}}\left(\boldsymbol{r}^{\prime \prime}\right)\right\rangle_{0}}-c_{2}^{k^{\prime \prime} k^{\prime}}\left(\boldsymbol{r}^{\prime \prime}, \boldsymbol{r}^{\prime}\right)\right) \\
= & \frac{k_{\mathrm{B}} T}{m_{k}}\left(\delta_{k k^{\prime}} \delta\left(\boldsymbol{r}-\boldsymbol{r}^{\prime}\right)-f_{1}^{k}(\boldsymbol{r}) \cdot c_{2}^{k k^{\prime}}\left(\boldsymbol{r}^{\prime}, \boldsymbol{r}^{\prime}\right)\right), \\
\lambda_{2}^{k k^{\prime}}\left(\boldsymbol{r}_{l}, \boldsymbol{r}_{l^{\prime}}\right)= & \sum_{l^{\prime \prime}} \sum_{k^{\prime \prime}} \int_{V_{l^{\prime \prime}}} \mathrm{d} \boldsymbol{r}_{l^{\prime \prime}}\left(\left\langle\hat{\boldsymbol{j}}^{k}\left(\boldsymbol{r}_{l}\right) \ddot{\hat{\boldsymbol{j}}^{k^{\prime \prime}}}\left(\boldsymbol{r}_{l^{\prime \prime}}\right)\right\rangle_{0}+\frac{N_{k}}{V_{l}} \frac{N_{k^{\prime \prime}}}{V_{l^{\prime \prime}}} \frac{\left(k_{\mathrm{B}} T\right)^{2}}{m_{k} m_{k^{\prime \prime}}}\right. \\
& \left.\times \frac{\partial}{\partial \boldsymbol{r}_{l}} \frac{\partial}{\partial \boldsymbol{r}_{l^{\prime \prime}}}\left\{f_{1}^{k}\left(\boldsymbol{r}_{l}\right) f_{1}^{k^{\prime \prime}}\left(\boldsymbol{r}_{l^{\prime \prime}}\right)\left[\tilde{\Phi}_{n n}^{-1}\left(\boldsymbol{r}_{l}, \boldsymbol{r}_{l^{\prime \prime}}\right)\right]_{k k^{\prime \prime}}\right\}\right)\left[\tilde{\Phi}_{n n}^{-1}\left(\boldsymbol{r}_{l^{\prime \prime}}, \boldsymbol{r}_{l^{\prime}}\right)\right]_{k^{\prime \prime} k^{\prime}}, \\
\bar{\lambda}_{2}^{k k^{\prime}}\left(\boldsymbol{r}, \boldsymbol{r}^{\prime}\right)= & \lambda_{2}^{k k^{\prime}}\left(\boldsymbol{r}, \boldsymbol{r}^{\prime}\right) / \lambda_{0}^{k k^{\prime}}\left(\boldsymbol{r}, \boldsymbol{r}^{\prime}\right) .
\end{aligned}
$$

Inserting (7) and (8) in (1), we get the flux

$$
\hat{\boldsymbol{j}}^{k}(\boldsymbol{r} ; t)=D^{k k}(\boldsymbol{r}) \frac{\partial}{\partial \boldsymbol{r}} \delta n^{k}(\boldsymbol{r} ; t)+\sum_{k^{\prime}} \int \mathrm{d} \boldsymbol{r}^{\prime} \bar{D}^{k k^{\prime}}\left(\boldsymbol{r}, \boldsymbol{r}^{\prime}\right) \frac{\partial}{\partial \boldsymbol{r}^{\prime}} \delta n^{k^{\prime}}\left(\boldsymbol{r}^{\prime} ; t\right),
$$

where

$$
D^{k k}(\boldsymbol{r})=D^{k}(\boldsymbol{r})=\frac{k_{\mathrm{B}} T}{m_{k}} \sqrt{\frac{\pi}{2 \bar{\lambda}_{2}^{k k}(\boldsymbol{r})}}
$$

is an inhomogeneous self-diffusion coefficient for a $k$-species particle with respect to the membrane surface in the initial electrolyte solution phase, while

$$
\bar{D}^{k k^{\prime}}\left(\boldsymbol{r}, \boldsymbol{r}^{\prime}\right)=\frac{k_{\mathrm{B}} T}{m_{k}} f_{1}^{k}(\boldsymbol{r}) c_{2}^{k k^{\prime}}\left(\boldsymbol{r}, \boldsymbol{r}^{\prime}\right) \sqrt{\frac{\pi}{2 \lambda_{2}^{k k^{\prime}}(\boldsymbol{r})}}
$$


is that of interdiffusion for $k, k^{\prime}$-species particles.

At last, on the basis of the explicit form for inverse functions (6) and definition (10), $\bar{\lambda}_{2}^{k k}(\boldsymbol{r})$ has the following form:

$$
\begin{aligned}
\bar{\lambda}_{2}^{k k}(\boldsymbol{r}) & = \\
= & \frac{1}{3 m_{k}}\left[\frac{\partial^{2}}{\partial \boldsymbol{r}^{2}} U_{k}(\boldsymbol{r})+\sum_{k^{\prime}} \frac{N_{k^{\prime}}}{V_{1}} \int \frac{\partial^{2}}{\partial \boldsymbol{r}^{2}} U_{k k^{\prime}}\left(\boldsymbol{r}, \boldsymbol{r}^{\prime}\right) f_{1}^{k^{\prime}}\left(\boldsymbol{r}^{\prime}\right) g_{2}^{k k^{\prime}}\left(\boldsymbol{r}, \boldsymbol{r}^{\prime}\right) \mathrm{d} \boldsymbol{r}^{\prime}\right] \\
& +\frac{5}{3 m_{k}}\left[\frac{\partial^{2}}{\partial \boldsymbol{r}^{2}} U_{k}(\boldsymbol{r})+\sum_{k^{\prime}} \frac{N_{k^{\prime}}}{V_{1}} \int f_{1}^{k^{\prime}}\left(\boldsymbol{r}^{\prime}\right)\left(\frac{\partial^{2}}{\partial \boldsymbol{r}^{2}} U_{k k^{\prime}}\left(\boldsymbol{r}, \boldsymbol{r}^{\prime}\right) g_{2}^{k k^{\prime}}\left(\boldsymbol{r}, \boldsymbol{r}^{\prime}\right)\right.\right. \\
& \left.\left.+\frac{\partial}{\partial \boldsymbol{r}} U_{k k^{\prime}}\left(\boldsymbol{r}, \boldsymbol{r}^{\prime}\right) \frac{\partial}{\partial \boldsymbol{r}} g_{2}^{k k^{\prime}}\left(\boldsymbol{r}, \boldsymbol{r}^{\prime}\right)\right) \mathrm{d} \boldsymbol{r}^{\prime}\right]
\end{aligned}
$$

where $g_{2}^{k k^{\prime}}\left(\boldsymbol{r}, \boldsymbol{r}^{\prime}\right)$ are pair correlation functions, $f_{1}^{k}(\boldsymbol{r})$ - density profiles, $U_{k}(\boldsymbol{r})$ and $U_{k k^{\prime}}\left(\boldsymbol{r}, \boldsymbol{r}^{\prime}\right)$ are interaction potentials defined in the next chapter. The quantity $\bar{\lambda}_{2}^{k k}(\boldsymbol{r})$ is an analogue of the friction constant $\gamma^{2}$ for particle diffusion in a medium. One can be convinced of the fact that considering a bulk case, when $U_{k}(\boldsymbol{r}) \equiv 0$, $f_{1}^{k^{\prime}}\left(\boldsymbol{r}^{\prime}\right) \equiv 1, g_{2}^{k k^{\prime}}\left(\boldsymbol{r}, \boldsymbol{r}^{\prime}\right)=g_{2}^{k k^{\prime}}\left(\left|\boldsymbol{r}-\boldsymbol{r}^{\prime}\right|\right)$, namely, the classical result of S.Rice is recovered [16]. An advantage of expression (14) is in the appearance of a position dependent friction constant for an inhomogeneous system. It should also be noted that $\bar{\lambda}_{2}^{k k}(\boldsymbol{r})$ describes self-diffusion between $k$-species particles but equally treats other species which form a combined medium for the given particles. It is clear that equation (14) may be applied to any inhomogeneous system with its microscopic characteristics.

\section{Numerical results and conclusions}

As mentioned above, equilibrium theories do not provide an exact behaviour of the direct correlation function $c_{2}^{k k^{\prime}}\left(\boldsymbol{r}, \boldsymbol{r}^{\prime}\right)$, especially at small distances. So we restrict ourselves to the estimate of self-diffusion coefficients for the salt $\mathrm{NaCl}$ in the vicinity of the reverse osmosis membrane within the described model. To do it on the basis of equations (12), (14) one needs the density profiles, pair correlation functions and interaction potentials. The problem was solved in [13]. Here we only remind the necessary results.

The singlet potential $U_{k}(\boldsymbol{r})$ consists of a trivial Gibbs part

$$
\varphi^{\mathrm{w}}\left(z_{i}\right)=\left\{\begin{array}{cc}
\infty, & \left|z_{i}\right|<\sigma / 2 \\
0, & \left|z_{i}\right|>\sigma / 2
\end{array}\right.
$$

and an electrostatic interaction with its own image:

$$
U_{\mathrm{im}}^{\mathrm{w}}\left(z_{i}\right)=\frac{\varepsilon_{1}-\varepsilon_{2}}{\varepsilon_{1}+\varepsilon_{2}} \frac{Z_{i}^{2} e^{2}}{2 z_{i}}
$$

where $z_{i}$ and $Z_{i}$ are the distances from the membrane and the ionic charge, respectively. In the case of pair interaction there are three different potentials, namely, 
the hard-sphere one

$$
\varphi\left(r_{i j}\right)=\left\{\begin{array}{cc}
\infty, & \left|\mathbf{r}_{i j}\right|<\sigma \\
0, & \left|\mathbf{r}_{i j}\right|>\sigma
\end{array}\right.
$$

the Coulomb potential for charges $Z_{i}, Z_{j}$

$$
U_{\mathrm{C}}^{\mathrm{b}}\left(r_{i j}\right)=\frac{Z_{i} Z_{j} e^{2}}{r_{i j}}
$$

and the interaction of the $i$-th ion with the $j$-th ion's image

$$
U_{\mathrm{im}}^{\mathrm{b}}\left(r_{i j}^{\prime}\right)=\frac{Z_{i} Z_{j} e^{2}}{r_{i j}^{\prime}} \frac{\varepsilon_{1}-\varepsilon_{2}}{\varepsilon_{1}+\varepsilon_{2}},
$$

where $r_{i j}^{\prime}$ is a distance between them.

The inhomogeneous distribution near the planar wall can be described by the singlet $f_{1}^{k}\left(z_{1}\right)$ and pair $f_{2}^{k k^{\prime}}\left(z_{1}, z_{2}, r_{12}\right)$ densities which are to be found. In our case of a symmetric 1:1 electrolyte the following relations are valid:

$$
\begin{gathered}
f_{1}^{+}\left(z_{1}\right)=f_{1}^{-}\left(z_{1}\right)=f\left(z_{1}\right), \\
f_{2}^{++}\left(z_{1}, z_{2}, r_{12}\right)=f_{2}^{--}\left(z_{1}, z_{2}, r_{12}\right), \quad f_{2}^{+-}\left(z_{1}, z_{2}, r_{12}\right)=f_{2}^{-+}\left(z_{1}, z_{2}, r_{12}\right),
\end{gathered}
$$

where "+" denotes positive particles, while "-" - negative ones. The functions are coupled by the first equation of the BBGKY chain [13]:

$$
\begin{aligned}
& \frac{\mathrm{d} f\left(z_{1}\right)}{\mathrm{d} z_{1}}+\frac{\mathrm{d} U_{1}\left(z_{1}\right)}{\mathrm{d} z_{1}} f\left(z_{1}\right) \\
& +\rho \int_{V} \frac{\partial}{\partial z_{1}} \varphi\left(r_{12}\right)\left[f_{2}^{++}\left(z_{1}, z_{2}, r_{12}\right)+f_{2}^{+-}\left(z_{1}, z_{2}, r_{12}\right)\right] \mathrm{d} \boldsymbol{r}_{2} \\
& +\rho \int_{V} \frac{\partial}{\partial z_{1}} U_{\mathrm{C}}^{++}\left(r_{12}\right)\left[f_{2}^{++}\left(z_{1}, z_{2}, r_{12}\right)-f_{2}^{+-}\left(z_{1}, z_{2}, r_{12}\right)\right] \mathrm{d} \boldsymbol{r}_{2} \\
& +\rho \int_{V} \frac{\partial}{\partial z_{1}} U_{\mathrm{im}}^{++}\left(r_{12}^{\prime}\right)\left[f_{2}^{++}\left(z_{1}, z_{2}, r_{12}\right)+f_{2}^{+-}\left(z_{1}, z_{2}, r_{12}\right)\right] \mathrm{d} \boldsymbol{r}_{2}=0 .
\end{aligned}
$$

It is closed by the superposition approximation

$$
f_{2}^{++}\left(z_{1}, z_{2}, r_{12}\right)=f\left(z_{1}\right) F_{\mathrm{hs}}^{0}\left(r_{12}\right) \exp \left\{ \pm G\left(z_{1}, z_{2}, r_{12}\right)\right\},
$$




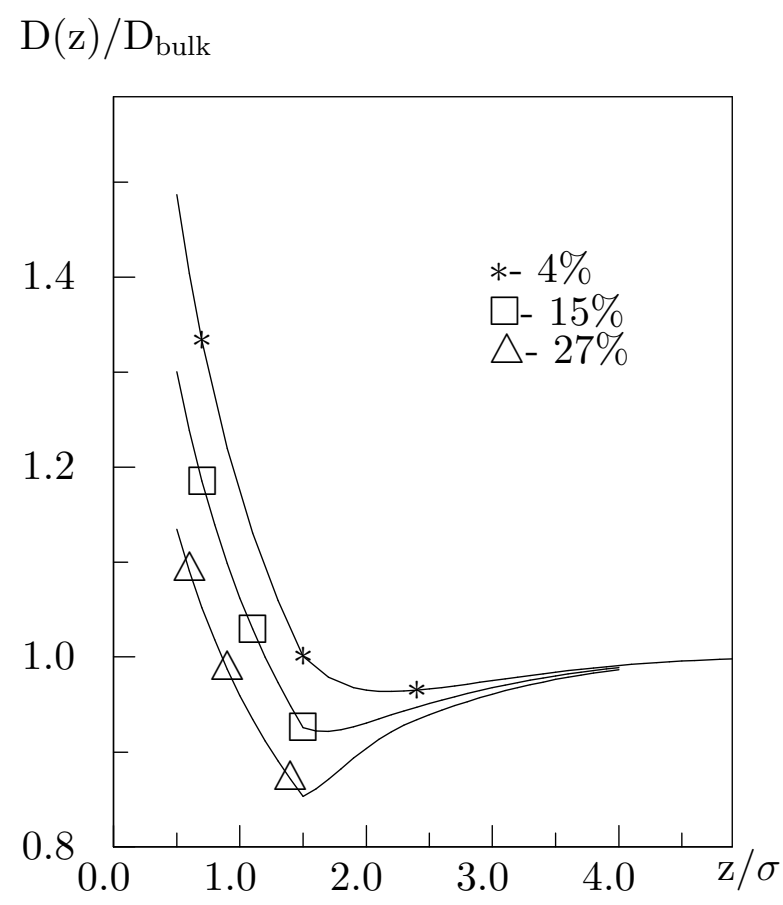

Figure 2. Self-diffusion coefficients for $\mathrm{Na}^{+}$ and $\mathrm{Cl}^{-}$ions in water near the reverse osmosis membrane at various mass concentrations wherein $F_{\text {hs }}^{0}\left(r_{12}\right)$ is a pair distribution function for hard spheres, $G\left(z_{1}, z_{2}, r_{12}\right)$ is responsible for the inhomogeneous electrostatic contribution. The latter, along with $U_{1}\left(z_{1}\right)$, is discussed in detail in [13]. Equation (21) was solved for an aqueous $\mathrm{NaCl}$ solution $\left(\varepsilon_{1}=81\right)$ near a frequently used polymeric membrane with $\varepsilon_{2}=$ 4 at temperature $25^{\circ} \mathrm{C}$. The diameters $\sigma$ for both $\mathrm{Na}$ and $\mathrm{Cl}$ ions were assumed to be $3.9 \AA$. Numerical calculations for three mass concentrations (4\%-sea water, $27 \%$-the highest concentration at $25^{0} \mathrm{C}$ ) are depicted in figure 1 . In all the cases negative adsorption is observed. The contact value increases with the rise of concentration, while the density maximum shifts closer to the membrane. It can be explained by the fact that structural ordering is more intensive for larger concentrations in comparison with the Coulomb inter-

action. However, all the solutions achieve the bulk properties almost simultaneously, namely, at $z \approx 4 \sigma-5 \sigma$.

Now let us focus on the diffusion coefficients in accordance with equation (12). It is easy to see that electrolyte symmetry due to Coulomb interactions makes some quantities entering (14) equivalent. Thus, the set of equalities (20) may be extended by those for a single particle interaction

$$
U_{1}^{+}\left(z_{1}\right)=U_{1}^{-}\left(z_{1}\right)=U_{1}\left(z_{1}\right),
$$

which is used in (21) and for a pair potential

$$
\begin{aligned}
& U_{++}\left(\boldsymbol{r}, \boldsymbol{r}_{0}\right)=U_{--}\left(\boldsymbol{r}, \boldsymbol{r}_{0}\right), \\
& U_{+-}\left(\boldsymbol{r}, \boldsymbol{r}_{0}\right)=U_{-+}\left(\boldsymbol{r}, \boldsymbol{r}_{0}\right) .
\end{aligned}
$$

Instead of the inhomogeneous pair correlation function $g_{2}$, the same bulk one is accepted to simplify the calculations. For qualitative estimates the masses of $\mathrm{Na}$ and $\mathrm{Cl}$ ions are assumed to be equal. Then their diffusion coefficients coincide, too:

$$
D^{++}(\boldsymbol{r})=D^{--}(\boldsymbol{r})=D(\boldsymbol{r}) .
$$

In contrast to the evaluation of distribution functions, Coulomb interaction is excluded from pair potentials for the friction constant $\bar{\lambda}_{2}^{k k}(\boldsymbol{r})(14)$, because the 
effect of particle dimensions is dominant especially at high densities typical of a liquid. However, electrostatics has an effect through the distribution function (21) which is calculated with the total potential (hard spheres plus Coulomb). With all the assumptions we arrive at the following:

$$
D(z)=\frac{D_{\text {bulk }}}{\sqrt{A(z)+B(z)+C(z)}},
$$

where

$$
\begin{aligned}
A(z) & =3 / 4 \frac{\Delta U(z)}{\pi N / V \sigma^{3} g_{2}(\sigma)}, \\
B(z)= & 1 / 2 \int_{\operatorname{Max}(-z,-1)}^{1} f_{1}\left(z+z^{\prime}\right) \mathrm{d} z^{\prime}, \\
C(z)= & 5 / 4\left(-\int_{\operatorname{Max}(-z,-1)}^{1} f_{1}\left(z+z^{\prime}\right) \mathrm{d} z^{\prime}+f_{1}(z+1)+H(z-1) f_{1}(z-1)\right),
\end{aligned}
$$

$g_{2}(\sigma)$ is a contact value for the bulk hard sphere pair correlation function, $H(x)$ is the Heaviside unit function, $D_{\text {bulk }}$ is a bulk diffusion coefficient attained at high $z$, when $A(z) \rightarrow 0, B(z) \rightarrow 1, C(z) \rightarrow 0$. It exceeds the experimental value. This is not surprising, as the Markovian approximation was used to obtain (26), as well as other simplifications were made to treat the problem analytically. Thus, we put $D_{\text {bulk }}=1$ and focus our attention on the relative behaviour of $D(z)$.

In figure 2, qualitative self-diffusion coefficients for $\mathrm{Na}$ and $\mathrm{Cl}$ ions in the system "initial solution-membrane" are represented, as computed from (26). Intensive repulsion near the membrane (negative adsorption) brings about an overall rise of the coefficient at small distances where the effect of the term $A(z)$ is the most significant. Far from the membrane it monotonically tends to zero, while all the typical behaviour of the self-diffusion coefficient is determined by $B(z)$ and $C(z)$. $B(z)$ is responsible for the bulk value $D_{\text {bulk }}$ at $z \rightarrow \infty$. Refraction of the plot for the largest concentration at $z \approx 1.5 \sigma$ is caused by the hard sphere potential which has a step-like form and abruptly decreases the singlet density from a contact value to zero. So, expression (26) adequately describes the position dependent diffusion coefficient for ions near the dielectric membrane surface that operates on the basis of a negative adsorption phenomenon.

\section{References}

1. Lakshminarayanaiah N. Transport Phenomena in Membranes. N.-Y. and London, Academic Press, 1967, 517 p.

2. Dytnerskii Yu.I. Membrane Processes for Liquid Mixture Separation. Moscow, Khimiya, 1975, 229 p. (in Russian). 
3. Kozhevnikov N.E., Leonov A.I. Reverse Osmosis and Ultrafiltration. Reviews on Certain Productions of Chemical Industry. Moscow, Institute of experimental chemistry, 1973, No. 35, 21 p. (in Russian).

4. Lonsdale H.K. Theory and practice of reverse osmosis and ultrafiltration. In the book: Technological Processes Using Membranes, Moscow, Mir, 1976, p. 130-159 (in Russian).

5. Rade C.E. Principles of reverse osmosis. In the book: Technological Processes Using Membranes, Moscow, Mir, 1976, p. 115-130 (in Russian).

6. Dytnerskii Yu.I. Reverse Osmosis and Ultrafiltration. Moscow, Khimiya, 1978, 349 p. (in Russian).

7. Sourirajan S. Reverse Osmosis. London, Logos, 1979, 578 p.

8. Nikolayev N.I. Diffusion in Membranes. Moscow, Khimiya, 1980, 231 p. (in Russian).

9. Dukhin S.S., Churayev N.V., Shilov V.N., Starov V.M. Problems of reverse osmosis simulation. // Uspekhi Khimii, 1988, vol. 57, No 6, p. 1010-1030 (in Russian).

10. Nakagaki M. Physical chemistry of membranes. Moscow, Mir, 1991, 253 p. (in Russian).

11. Kuryliak I.J., Tokarchuk M.V. Statistical theory of electrolyte solutions transport through membrane structures. Diffusion coefficients. // Ukr. Fiz. Zhurn., 1991, vol. 36, No 8, p. 1179-1185 (in Ukrainian).

12. Tokarchuk M.V., Omelyan I.P., Zhelem R.I. On the statistical theory of electrolyte solution transport through membrane structures. Diffusion coefficients. // Cond. Mat. Phys., 1993, No 2, p. 94-102 (in Ukrainian).

13. Yukhnovskii I.R., Zhelem R.I., Omelyan I.P., Sovyak E.N., Tokarchuk M.V. Diffusion processes in the transport of electrolyte solutions through reverse osmosis membranes. Structural functions and diffusion coefficients. // Ukr. Fiz. Zhurn., 1996, vol. 41, No 9, p. 819-827 (in Ukrainian).

14. Hansen J.P., McDonald I.R. Theory of Simple Liquids. London, Academic Press, 2nd edition, 1990, $556 \mathrm{p}$.

15. Yukhnovskii I.R., Holovko M.F. Statistical Theory of Classical Equilibrium Systems. Kiev, Naukova Dumka, 1980, 372 p. (in Russian).

16. Rice S.A. An acoustic continuum model of molecular friction in simple dense fluid. // Molec. Phys., 1961, vol. 4, p. 305-310. 


\title{
Розрахунок функцій розподілу та коефіцієнтів дифузії іонів у системі “вихідний розчин електроліту - мембрана"
}

\author{
Р.І.Желем, М.В.Токарчук, І.П.Омелян, Є.М.Сов'як
}

Інститут фізики конденсованих систем НАН України, 290011 Львів, вул. Свєнціцького, 1

Отримано 14 липня 1998 р.

Розглядається дифузія іонів у неоднорідних умовах двофазної системи вихідний розчин електроліту - мембрана. 3 допомогою методу нерівноважного статистичного оператора отримано вирази для константи тертя, коефіцієнтів самодифузії та взаємної дифузії в неоднорідному випадку. Їх застосовано до даної системи, і розраховано поведінку коефіцієнта самодифузії для $\mathrm{NaCl}$, залежного від віддалі до зворотноосмотичної мембрани.

Ключові слова: дифузія в рідинах, процеси переносу, функція розподілу, осмос, мембрана

PACS: 05.60. $+w, 73.40,66.10 . \mathrm{Cb}, 82.65 . \mathrm{Fr}$ 